\title{
POTENTIAL DEMAND FOR NEW HIGH SPEED RAIL SERVICES IN HIGH DENSE AIR TRANSPORT CORRIDORS
}

\author{
C. ROMÁN \& J.C. MARTÍN \\ Departamento de Análisis Económico Aplicado, Universidad de Las Palmas de Gran Canaria, \\ 35017 Las Palmas G.C., Spain.
}

\begin{abstract}
Demand analysis is a key element in the evaluation of public policies. The ex ante evaluation of large scale projects involving for example new high speed rail (HSR) services requires the estimation of reliable choice models to predict ridership shares of the new alternatives and to identify the main sources for traffic diversion and traffic generation. This paper analyses and forecasts potential demand for HSR services in the high dense air transport route: the line Madrid-Barcelona. The model aims to explain changes in the demand for interurban rail and air transport as a result of substantial improvements in the level of service due to the introduction of the HSR. Results highlight that the expected volume of demand for the HSR in the corridor is not enough to guarantee a positive social benefit of this project.

Keywords: discrete choice modeling, intermodal competition stated preference, mixed RP/SP data.
\end{abstract}

\section{INTRODUCTION}

Congestion at roads and airports terminals, road accidents and greenhouse gas emissions, represent nowadays the main externalities of the transport systems. These negative effects have raised serious concerns about the impact of infrastructures on regional development, the competitiveness of the transport systems and the environmental quality. To improve intercity mobility, attention has been focused on evaluating alternative transportation services which provide an efficient response to incremental demand in the near future. These include, among others, upgrading conventional rail services to new high speed services using advanced technologies.

The impacts caused by investments in high speed rails (HSRs) have been analyzed in the literature in many different ways. Thus, we can classify the studies into the following groups: (i) general assessments [1-7]; (ii) evaluations of the economic profitability of particular corridors or areas, de Rus and Inglada [8, 9] for the HST Madrid-Sevilla, Levinson et al. [10] for Los Angeles-San Francisco, de Rus and Román [11] for the HST Madrid-Zaragoza-Barcelona, Steer Davies Gleave [12] and Atkins [13] for the case of the UK, de Rus and Nombela [14] for the European Union, and Martín and Nombela [15] for the case of Spain; (iii) assessments of the regional effects [16-19], studies of the impacts on accessibility [20-24] and, finally, regarding (iv) intermodal competition, Combes and Linnemer [25] studied the impacts of the creation of a new infrastructure connecting two points that coexists with old network infrastructure (like roads) using a game theoretic approach.

Demand analysis is a key element in the evaluation of public policies. Investment decisions in transport infrastructures cannot be made independently of the volume of potential demand in the influence area of the new infrastructure, because it determines to a large extent the social benefits of the project. The ex ante evaluation of large scale projects involving for example new HSR services requires the estimation of reliable choice models to predict ridership shares of the new alternatives and to identify the main sources for traffic diversion and traffic generation.

The analysis of the perceptions and preferences of passengers on interurban transport is not new in the literature. Discrete choice modeling is usually claimed as a proper methodology to assess and compare the preferences of passengers in the context of modal competition. The behavioral nature

(C) 2010 WIT Press, www.witpress.com

ISSN: 1743-7601 (paper format), ISSN: 1743-761X (online), http://journals.witpress.com DOI: $10.2495 /$ SDP-V5-N2-114-129 
of disaggregate discrete choice models has led to a widespread use of this tool in the field of travel demand modeling. Some recent applications in the context of intercity travel mode choice can be found in Refs. [26-34] among others.

The objective of this paper is to analyze and forecast potential demand for new HSR services, the Madrid-Barcelona route, entering in a market characterized by a high density air transport services, and then to compare the estimate and actual measured demand after the entrance of the HSR in the market. The analysis is based on the estimation of a disaggregate demand model that uses information about travelers preferences in the existing modes in this corridor. Preferences for the new HSR alternative are obtained from a stated choice experiment facing air plane users with this new option. The rest of the paper is organized as follows. Section 2 presents some relevant information about the market background. The main characteristics of the datasets used in the analysis are presented in Section 3. Section 4 provides the demand model as well as estimation results. An analysis of potential demand and potential competition of the HSR with air transport is presented in Section 5. Finally, our main conclusions are presented in Section 6.

\section{MARKET BACKGROUND}

Rail sector has received considerable attention within the European transport policy during the past decades, focusing more recently on the development of the HSR networks. Spain has adopted this policy and will account by 2010 with one of the densest HSR network in the world, with more kilometers than Japan and France, countries that have been pioneers in the development of their HSR networks (Table 1). In fact, the Spanish Infrastructure Master Plan has considered an expenditure of nearly 250 billion Euros in the development of the HSR until the year 2020, and by this time, the Spanish network is expected to reach $10,000 \mathrm{~km}$.

Figure 1 shows the Spanish HSR network. Some lines are in operation (in green), some under construction (in yellow), some are planned (in red) and some other are in study (in pink). The picture gives an idea of the density of the network in the future.

The new HSR link between Madrid and Barcelona is a good example of this type of policy. Madrid and Barcelona are the most important metropolitan areas of Spain with five and three million of inhabitants, respectively; they represent important centers of economic activity and there are more than seven million trips per year. Regarding this line, the main difference with respect to the policy followed within the European Union is that Spain accounts with a very good level of other transport facilities linking these two cities. Until the inauguration of the HSR line in February 2008, RENFE provided rail services using conventional trains (Talgo) that connected the two cities in $5 \mathrm{~h}$ and 30 min offering a service frequency of eight departures per day in each direction. There is a $625-\mathrm{km}$ motorway connecting these two cities in about $6 \mathrm{~h}$ and $20 \mathrm{~min}$ (being the link Zaragoza-Barcelona a toll road). Madrid and Barcelona are also connected by air shuttle and regular services and this route has recently become the most important domestic market in the world, with near five million passengers per year. This route is comparable, in terms of traffic, with other important domestic markets, e.g. Sao Paulo-Rio de Janeiro, Melbourne-Sydney, and Cape Town-Johannesbourg (Table 2).

Table 1: Length of the HSR networks.

\begin{tabular}{lc}
\hline Country & HSR network (km) \\
\hline Spain (year 2010) & 2,230 \\
Japan (Shinkansen) & 2,090 \\
France (TGV) & 1,893 \\
\hline
\end{tabular}




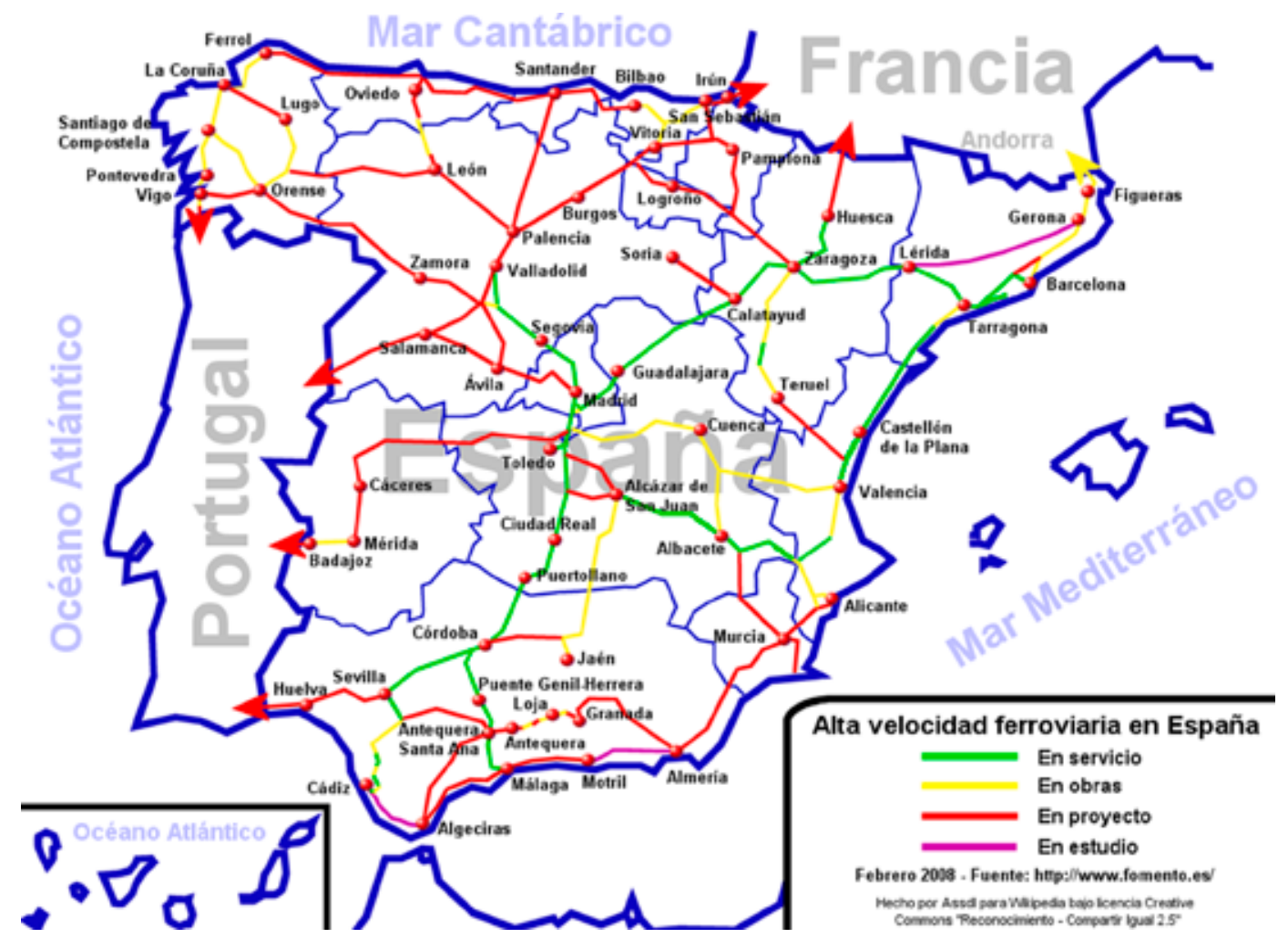

Figure 1: High speed railway network in Spain. Year 2008.

Table 2: High dense air domestic markets.

\begin{tabular}{lc}
\hline Route & Flights per week \\
\hline Madrid-Barcelona & 971 \\
Sao Paulo-Rio de Janeiro & 894 \\
Melbourne-Sydney & 851 \\
Cape Town-Johannesbourg & 831 \\
\hline
\end{tabular}

Source: OAG BACK Aviation Solutions.

The new high speed train (HST) replaced conventional train services and entered in the market with the objective of attracting new passengers and deviating traffic from the air transport (the principal mode in the route), offering an improved level of service. In Table 3 we compare the main service attributes of the HST with the rest of the modes.

As we can see, the HST improves substantially the level of service of the conventional train in terms of travel time (50\% reduction) and service frequency (more than 50\% increment in departures per day). This new alternative represents a close substitute of the air transport mode, but while total travel time (in vehicle plus waiting time) is similar in both modes, the plane is still very competitive in service frequency. In fact, one of the air sector reactions to the HST entrance was to use planes of reduced size in order to maintain a good level of service frequency. 


\section{DATA COLLECTION}

\subsection{The sample selection}

A survey of travelers in the Madrid-Barcelona corridor was conducted in order to obtain information about the principal modes of transport: car driver, car passenger, bus, conventional train, and airplane. Data were collected during the second term of the year 2004, avoiding vacation periods (Easter and local holidays). At this time, the HST was already operating between Madrid and Zaragoza, but rail services between Madrid and Barcelona were still provided by conventional trains. A specific revealed preference (RP) questionnaire was designed for each mode of transport. As the main purpose of the research was to study the potential demand for the new HST alternative to stated choice (SC) experiment was included in the questionnaire of plane users as this mode was thought to be a close substitute of the new service.

A choice-based sample was selected in order to ensure that sufficient observations are obtained for each of the modes currently chosen by each traveler. Modal shares in the sample were determined trying to replicate modal shares in the population, given the available information at the time the surveys were carried out and considering a maximum error of $10 \%$ [35]. Table 4 presents the modal share in the sample. Air travel is by far the dominant mode in this corridor, transporting over $66 \%$ of travelers. Car travel is the next largest market (12\%), followed by train (11\%) and bus (8\%).

The survey was randomly administered to bus, train and plane travelers through personal interviews. Bus users were interviewed in the bus station, train users inside the train, while air transport users were approached at the corresponding boarding gates at the Barajas Airport (Madrid). For the latter, interviews were completed with the aid of personal computers that allowed us to implement a stated choice experiment (facing the actual alternative with the new HST) according to the current trip experience. Flights and scheduled trips by bus and train were sampled over 1 week and at various times of the day in order to capture both peak and off peak travelers. A self-administered

Table 3: Comparison of the main service attributes.

\begin{tabular}{|c|c|c|c|c|c|}
\hline Attribute & HST & Plane & Conventional train & Car & Bus \\
\hline $\begin{array}{l}\text { Travel time (in vehicle) } \\
\text { Fare/(fuel + toll): }\end{array}$ & $2 \mathrm{~h} 38 \mathrm{~min}$ & $1 \mathrm{~h}$ & $5 \mathrm{~h} 30 \mathrm{~min}$ & $\begin{array}{l}6 \mathrm{~h} 22 \mathrm{~min} \\
70.52 €\end{array}$ & $8-9 \mathrm{~h}$ \\
\hline Regular & $102 €$ & $96 €$ & $65 €$ & $(24.15 €$ toll $)$ & $28 €-35 €-41 €$ \\
\hline Shuttle service & $163 €$ & $199 €$ & & (46.37€ fuel) & \\
\hline $\begin{array}{l}\text { Frequency (departures/ } \\
\text { day one way) }\end{array}$ & 18 & 138 & 8 & & 26 \\
\hline
\end{tabular}

Table 4: Modal share in the sample.

\begin{tabular}{lcc}
\hline Mode & Travelers & $\%$ \\
\hline Car driver & 38 & 8.62 \\
Car passenger & 18 & 4.08 \\
Bus & 39 & 8.84 \\
Train (conventional) & 51 & 11.56 \\
Plane & 295 & 66.89 \\
\hline
\end{tabular}


questionnaire was randomly distributed to motorist traveling between Madrid and Barcelona. Individuals were located at petrol stations strategically placed in the national motorway A-II and were asked to complete the questionnaire and mail it back.

\subsection{The revealed preference questionnaire}

In all cases, the RP questionnaire was divided into four sections of questions: identification data, current trip information, household information and personal information. Details of the current trip included trip origin and destination, travel cost, time spent on the main travel mode, access and egress mode and the time taken to access and egress the main mode, waiting time, trip purpose, trip frequency, habitual mode for a similar trip, and other details needed to measure the attributes of the non-chosen alternatives. Socioeconomic information was collected at household and individual level. Household questions included: members in the household, number of cars and household income. Individual level questions include: age, gender, education level, activity, number of working hours, job position and personal income.

In our sample, total travel time by plane ( $3 \mathrm{~h} 10 \mathrm{~min}$ ) is substantially less than in the rest of the modes (6 h $20 \mathrm{~min}$ in car, $7 \mathrm{~h} 8 \mathrm{~min}$ in train and $9 \mathrm{~h} 39 \mathrm{~min}$ in bus) but, in this mode the proportion of access and egress time reaches about $70 \%$ of the total trip duration. Nearly $56 \%$ of trips were mandatory (work and education) being this percentage over $60 \%$ for plane and train travelers. The highest proportion of non-mandatory trips is found among bus travelers (74\%). Regarding gender, $54 \%$ of travelers were men. We also observed substantial differences in per capita weekly income, ranging from $167 €$ for car passengers to $351 €$ for plane users.

Table 5 shows the classification of the habitual mode used for a similar trip in terms of the chosen mode for this trip. Figures show that most of plane users $(85.76 \%)$, use regularly this mode for traveling between Madrid and Barcelona, and rarely use conventional train and bus. This is not the case for the rest of the modes where the fidelization rate does not exceed 52\%. Also a substantial percentage of people in the sample who chose car declared that this was their first trip. This percentage is very low for plane users ( $7.12 \%$ ) which demonstrate that this segment (plane users) corresponds to frequent travelers.

\subsection{The stated choice experimental design}

Given that the HSR services were not currently available at the time this study, the ability to predict HSR market share using RP information about the existing modes is not possible. For this reason, a SC experiment was designed and included in the questionnaire devoted to plane travelers. The experiment creates hypothetical choice situations facing plane users with the new HSR alternative. These choice scenarios are created using the actual trip context to give the experiment more realism.

Table 5: Chosen mode vs. habitual mode.

\begin{tabular}{lrrrrr}
\hline \multirow{2}{*}{$\begin{array}{l}\text { Chosen } \\
\text { mode }\end{array}$} & \multicolumn{5}{c}{ Habitual mode (\%) } \\
\cline { 2 - 6 } & Plane & \multicolumn{1}{c}{ Car } & Train & \multicolumn{1}{c}{ Bus } & First trip \\
\hline Plane & 85.76 & 5.08 & 1.69 & 0.34 & 7.12 \\
Car & 10.71 & 41.07 & 8.93 & 5.36 & 33.93 \\
Train & 13.73 & 13.73 & 47.06 & 0.00 & 25.49 \\
Bus & 0.00 & 10.26 & 0.00 & 51.28 & 38.46 \\
\hline
\end{tabular}


The attributes included in the experiment represent typical level-of-service variables like travel time, access time, travel cost and headway (time between two consecutive services). We also include the latent variables reliability and comfort. This set of variables helped us to define the global quality of the alternative in each choice situation. In order to simplify the exercise and reduce the respondent burden (avoiding unnecessary biases), the effect of other attributes, such as the waiting time, was measured only in the RP context. (Other reason for not including waiting time in the SP experiment is that a substantial amount of this time is imposed by the safety control regulations at airports and it is out of control of the managers of the transport system.) All the effects are posteriorly included in the hybrid utility constructed in the mixed RP/SP estimation method.

To gain realism, the levels assigned to some attributes in the SC exercise were customized to each respondent experience pivoting the information provided by the RP questions around the reference alternative (the plane, in this case). Thus, the levels of travel cost and access time were defined in terms of the values experienced by the sample respondents and plausible percentage variations according to the available information about future fares and access time for the HSR were also considered.

The attribute levels used in the SC experiment are summarized in Table 6.

Table 6: Attributes and levels.

\begin{tabular}{|c|c|c|c|c|c|}
\hline \multirow[b]{2}{*}{ Attributes } & \multirow[b]{2}{*}{ Levels } & \multicolumn{4}{|c|}{ Mode } \\
\hline & & \multicolumn{2}{|c|}{ Plane } & \multicolumn{2}{|c|}{ HSR } \\
\hline Travel cost $\left(c_{v}\right)$ & $\begin{array}{l}0 \\
1 \\
2\end{array}$ & \multicolumn{2}{|c|}{$\begin{array}{c}c_{v} \times 1.10 \\
c_{v} \\
c_{v} \times 0.90\end{array}$} & \multicolumn{2}{|c|}{$\begin{array}{c}c_{v} \\
c_{v} \times 0.90 \\
c_{v} \times 0.80\end{array}$} \\
\hline Travel time $\left(t_{v}\right)$ & $\begin{array}{l}0 \\
1 \\
2\end{array}$ & $\begin{array}{l}1 \mathrm{~h} \\
1 \mathrm{~h}\end{array}$ & $\min$ & $\begin{array}{l}2 \mathrm{~h} 4 \\
2 \mathrm{~h} 3 \\
2 \mathrm{~h} 1\end{array}$ & $\begin{array}{l}\min \\
\min \\
\min \end{array}$ \\
\hline $\begin{array}{l}\text { Access }+ \text { egress } \\
\text { time }\left(t_{a}\right)\end{array}$ & $\begin{array}{l}0 \\
1 \\
2\end{array}$ & \multicolumn{2}{|c|}{$\begin{array}{c}t_{a} \times 1.20 \\
t_{\mathrm{a}} \\
t_{a} \times 0.80\end{array}$} & \multicolumn{2}{|c|}{$\begin{array}{c}t_{a} \\
t_{a} \times 0.90 \\
t_{a} \times 0.80\end{array}$} \\
\hline $\begin{array}{l}\text { Frequency } \\
\text { (headway) }(f)\end{array}$ & $\begin{array}{l}0 \\
1\end{array}$ & $\begin{array}{c}\text { Departure } \\
\text { before 9:00 } \\
\text { Every } 30 \mathrm{~min} \\
\text { Every } 15 \mathrm{~min}\end{array}$ & $\begin{array}{c}\text { Departure } \\
\text { after 9:00 } \\
\text { Every } 60 \mathrm{~min} \\
\text { Every } 30 \mathrm{~min}\end{array}$ & $\begin{array}{c}\text { Departure } \\
\text { before 9:00 } \\
\text { Every } 60 \mathrm{~min} \\
\text { Every } 30 \mathrm{~min}\end{array}$ & $\begin{array}{c}\text { Departure } \\
\text { after 9:00 } \\
\text { Every } 90 \mathrm{~min} \\
\text { Every } 60 \mathrm{~min}\end{array}$ \\
\hline Reliability ( $r$ ) & $\begin{array}{l}1 \\
2\end{array}$ & $\begin{array}{r}30 \mathrm{~m} \\
\text { (Inside } \\
15 \mathrm{~m} \\
\text { (in the b } \\
\text { Departu }\end{array}$ & $\begin{array}{l}\text { delay } \\
\text { le plane) } \\
\text { delay } \\
\text { ding gate) } \\
\text { on time }\end{array}$ & $10 \mathrm{mi}$ & elay \\
\hline Comfort $(C)$ & 0 & $\begin{array}{r}\mathrm{L} \\
\text { Small } \\
\text { Narrc } \\
\mathrm{H} \\
\text { Ample } \\
\text { Wid }\end{array}$ & $\begin{array}{l}\text { v: } \\
\text { room } \\
\text { seats } \\
\text { h: } \\
\text { g room } \\
\text { eats }\end{array}$ & $\begin{array}{r}\mathrm{H} \\
\text { Ample } \\
\text { Wid }\end{array}$ & room \\
\hline
\end{tabular}

$c_{v}=$ travel cost in plane.

$t_{a}=$ access + egress time in plane. 
An experimental design consisting in nine scenarios for each alternative was created using the program WINMINT (a standard software, developed by Rand Europe http://www.hpgholding.nl/ (the former Hague Consulting Group (HCG)), which is frequently used to conduct SC experiments). Table 7 presents the combination of attribute levels in the experimental design. The program automatically created nine different choice sets for each person, selecting at random one scenario in each alternative. Thus, for example, if the scenario 3 was selected for the plane and the scenario 8 for the HSR, the choice set in Table 8 would be presented to the traveler.

Thus, every respondent (i.e. the 295 plane users) provided nine stated preference (SP) observations obtaining a total of 2,655 statistical observations. After removing 179 inconsistent responses (those where the individual chose the worse alternative), we obtained a mixed RP/SP database of 2,917 observations.

\section{THE DEMAND MODEL}

Discrete choice models have been widely used to study consumers' behavior. The main interest lies on their ability to predict decision maker's choices and to analyze demand response to changes in the

Table 7: Attribute levels in the experimental design.

\begin{tabular}{|c|c|c|c|c|c|c|c|c|c|c|c|c|}
\hline \multirow[b]{2}{*}{ Scenario } & \multicolumn{6}{|c|}{ Plane (attribute levels) } & \multicolumn{6}{|c|}{ HSR (attribute levels) } \\
\hline & $c_{v}$ & $t_{v}$ & $t_{a}$ & $r$ & $f$ & $C$ & $c_{v}$ & $t_{v}$ & $t_{a}$ & $r$ & $f$ & $C$ \\
\hline 1 & 0 & 0 & 0 & 0 & 0 & 0 & 0 & 0 & 0 & 0 & 0 & 1 \\
\hline 2 & 0 & 1 & 1 & 2 & 0 & 1 & 0 & 1 & 1 & 2 & 0 & 1 \\
\hline 3 & 0 & 2 & 2 & 1 & 0 & 0 & 0 & 2 & 2 & 1 & 0 & 1 \\
\hline 4 & 1 & 0 & 1 & 1 & 1 & 0 & 1 & 0 & 1 & 1 & 1 & 1 \\
\hline 5 & 1 & 1 & 2 & 0 & 1 & 1 & 1 & 1 & 2 & 0 & 1 & 1 \\
\hline 6 & 1 & 2 & 0 & 2 & 1 & 0 & 1 & 2 & 0 & 2 & 1 & 1 \\
\hline 7 & 2 & 0 & 2 & 2 & 0 & 0 & 2 & 0 & 2 & 2 & 0 & 1 \\
\hline 8 & 2 & 1 & 0 & 1 & 0 & 1 & 2 & 1 & 0 & 1 & 0 & 1 \\
\hline 9 & 2 & 2 & 1 & 0 & 0 & 0 & 2 & 2 & 1 & 0 & 0 & 1 \\
\hline
\end{tabular}

Table 8: Example of choice situation.

\begin{tabular}{lcc}
\hline & Plane & HSR \\
\hline Travel cost & $99 €$ & $72 €$ \\
Travel time & $1 \mathrm{~h}$ & $2 \mathrm{~h} \mathrm{30} \mathrm{min}$ \\
Access + egress time & $36 \mathrm{~min}$ & $45 \mathrm{~min}$ \\
Reliability & 15 min delay & 5 min delay \\
Service frequency & Every 30 min & Every 60 min \\
Comfort & Low (small leg room) & High (ample leg room) \\
\hline
\end{tabular}

Actual Travel cost: $90 €$, Actual Access time: 45 min, Departure before 9:00

Which alternative do you prefer for a trip like this one?

Plane $\quad \square$ HSR


attributes of the alternatives. The classic model of rational choice is based on two fundamental properties: consistency and transitivity. The first implies that the same choice selection should be obtained under identical circumstances; the second provides a unique ordering of alternatives on a preference scale (see e.g. Ref. [36]). A choice among a set of alternatives requires the application of a decision rule. The utility maximization behavioral rule lies under the scheme of the rational choice and normally implies a compensatory decision process, i.e. individuals made trade-offs among attributes in determining the alternative with the highest utility. Since the analyst does not have full information about the utility of the decision maker $q$ for the alternative $j$, it is modeled as the sum of two components: a deterministic or observable utility $V_{j q}$, expressed in terms of a vector of attributes $\left(X_{j q}\right)$ of the alternative and a vector of socioeconomic characteristics of the individual $\left(S_{q}\right)$; and a random term $\varepsilon_{j q}$, representing the portion of utility unknown to the analyst. Thus, the true utility to the decision maker is represented by the random variable $U_{j q}=V_{j q}+\varepsilon_{j q}$; and therefore, the analyst, under the assumption of utility maximization, is only able to model the choice probability of the different alternatives.

Different assumptions about the distribution of the unobserved portion of utility $\varepsilon_{j q}$ result in different representations of the choice model. Thus, the famous multinomial logit (MNL) and nested logit (NL) models are obtained when $\varepsilon_{j q}$ are i.i.d. extreme value and a type of generalized extreme value, respectively (see Refs. [37,35] for more details about the derivation of choice probabilities in random utility models).

In this paper we use a mixed RP/SP data set. In order to obtain the same variance in the error terms for the RP $\left(\sigma_{\varepsilon}^{2}\right)$ and SP $\left(\sigma_{\eta}^{2}\right)$ utilities, a scale factor $\mu$ satisfying $\sigma_{\varepsilon}^{2}=\mu^{2} \sigma_{\eta}^{2}$ needs to be estimated [38]. Bradley and Daly [39] proposed an estimation method based on the construction of an artificial NL structure, usually referred as the 'Nested Logit trick', where RP alternatives are placed just below the root and each SP alternative is placed in a single-alternative nest with a common nest parameter $\mu$ [35].

We specified modal utility in terms of the main level-of-service attributes, namely, travel time $\left(t_{v}\right)$, travel cost $\left(c_{v}\right)$, waiting time $\left(t_{e}\right)$, access + egress time $\left(t_{a}\right)$ and service headway $(f)$. We considered a linear-in-the-parameter (but not linear-in-the-attributes) specification that included transport costs divided by the expenditure rate ( $g$, defined as per capita family income divided by available time, that is, total time per period (a week in this case) minus working hours) (following Jara-Díaz and Farah [40]). We also included cost squared terms divided by the expenditure rate and the income ( $I$, defined as per capita family income per week), as we obtained a significant proportion of money spent in transport, for the different modes, as recommended by Jara-Díaz [41]. This specification indicates that the marginal utility of the travel cost (which coincides with minus the marginal utility of income) varies with $g, I$ and $c_{v}$ yielding a different value for each individual. We also define two different interactions, namely $T$ (trip motive) with travel time and access + egress time with a dummy variable $T_{a}<60$ ( 1 , if access + egress time is less than $60 \mathrm{~min}, 0$ otherwise). The last dummy variable is used to capture the time intensity of this component on the total travel time. For the SP alternatives (the new HST and plane) the utility was defined in function of the attributes included in the choice experiment: travel time $\left(t_{v}\right)$, travel cost $\left(c_{v}\right)$, access + egress time $\left(t_{a}\right)$, service headway $(f)$, reliability $(r)$, expressed in terms of the delay time and comfort $(C)$. The latter was specified interacting with travel time in order to obtain the perception of comfort in terms of the duration of the trip as well as the perception of travel time in terms of the level of comfort. Regarding model structure we tested different NL structures for the RP alternatives. The best fit was found in the case of correlation between the plane and the conventional train.

Estimation results are shown in Table 9. All parameter estimates have the expected sign and are significant at a $95 \%$ confidence level, with the exception of the headway, the waiting time and the 
Table 9: Estimation results.

\begin{tabular}{|c|c|c|}
\hline Parameter & & Estimates $(t$-test $)$ \\
\hline Car driver constant & $C_{c c}$ & $\begin{array}{c}-3.8060 \\
(-3.1)\end{array}$ \\
\hline Car passenger constant & $C_{c a}$ & $\begin{array}{c}-4.7120 \\
(-3.4)\end{array}$ \\
\hline Bus constant & $C_{b}$ & $\begin{array}{c}-2.5810 \\
(-2.5)\end{array}$ \\
\hline Train constant & $C_{t}$ & $\begin{array}{c}-1.0000 \\
(-2.5)\end{array}$ \\
\hline Travel time $\left(t_{v}\right)$ & $\theta_{t v}$ & $\begin{array}{l}-0.0047 \\
(-2.8)\end{array}$ \\
\hline Travel cost $/ g\left(c_{v} / g\right)$ & $\theta_{c v / g}$ & $\begin{array}{l}-0.0572 \\
(-4.7)\end{array}$ \\
\hline Headway $(f)$ & $\theta_{f}$ & $\begin{array}{c}-0.0011 \\
(-0.5)\end{array}$ \\
\hline Travel $\operatorname{cost}^{2} / g I\left(c_{v}^{2} / g I\right)$ & $\theta_{c v 2 / g I}$ & $\begin{array}{c}0.0174 \\
(3.9)\end{array}$ \\
\hline Access + egress time $\left(t_{a}\right)$ & $\theta_{t a}$ & $\begin{array}{l}-0.0199 \\
(-4.9)\end{array}$ \\
\hline Waiting time $\left(t_{e}\right)$ & $\theta_{t e}$ & $\begin{array}{c}-0.0028 \\
(-0.4)\end{array}$ \\
\hline Travel time_Work + education $\left(t_{v} \times T\right)$ & $\theta_{t v_{-} T}$ & $\begin{array}{l}-0.0009 \\
(-1.0)\end{array}$ \\
\hline Access + egress time_T acc + egr $<60\left(T_{a<60} \times t_{a}\right)$ & $\theta_{t a \_} T a<60$ & $\begin{array}{c}0.0096 \\
(2.5)\end{array}$ \\
\hline Reliability (delay) ( $r$ ) & $\theta_{r}$ & $\begin{array}{l}-0.0180 \\
(-2.6)\end{array}$ \\
\hline Travel time $\times$ comfort high $\left(C \times t_{v}\right)$ & $\theta_{C_{-} t v}$ & $\begin{array}{l}0.0026 \\
(1.8)\end{array}$ \\
\hline HSR-Plane nest parameter & $\Phi$ & $\begin{array}{c}0.3651 \\
(3.2) \\
{[-5.62]^{*}}\end{array}$ \\
\hline Scale factor SP & $\mu$ & $\begin{array}{c}0.9026 \\
(3.2) \\
{[-0.34]^{*}}\end{array}$ \\
\hline$l^{*}(0)$ & & -2124.7995 \\
\hline$l^{*}(\theta)$ & & -1997.3985 \\
\hline Observations & & 2917 \\
\hline
\end{tabular}

$* t$-Test with respect to $\Phi=1$ and $\mu=1$.

interaction of travel time with trip motive. All the alternative specific constants (considering plane as reference) for the RP alternatives are significant and have negative sign, indicating that plane would be preferred if the effect of the other attributes were zero. We also obtained that the disutility produced by travel time increases as the level of comfort diminishes and that access + egress time 
produces more disutility to individuals who employ more than $60 \mathrm{~min}$ in access and egress to and from the airport or station.

\section{DEMAND FOR NEW HIGH SPEED RAIL SERVICES}

\subsection{Potential demand}

To obtain the choice probabilities, we apply the sample enumeration method [35] to individuals in the RP data base. Probabilities are computed from a hybrid utility containing common and noncommon RP/SP parameters (see Ref. [42] for more details). If attributes were only defined for the SP case (i.e. comfort, and reliability) their parameters must be scaled by $\mu$. However, those corresponding to attributes measured in the RP data base do not need to be scaled even if they only appear in the SP utility [43].

Table 10 presents the actual (without the HSR; this was the situation at the time this study was carried out and the alternatives were: car (driver and passenger), bus, conventional train and plane) and future (with the new HSR) predictions of the market share for the different modes. Actual market shares are obtained from the values of the different attributes in the RP sample for the existing alternatives. As the HSR will replace the conventional train, future market shares are obtained considering all the available information about this new alternative. This includes $50 \%$ reduction in travel time, 50\% increase in the service frequency and special reductions in fares for internet tickets. Thus, it is assumed a 30\% reduction in prices for individuals paying the tourist fare. According to this, the model predicts an entrance market share for the new HSR (without considering generated trips) of near 36\%, representing an increase of $190 \%$ for the share of the rail mode.

Considering a total demand of six million passengers per year in the most important modes of public transport (rail and plane), and considering different hypothesis about generated traffic (new trips produced as a result of the introduction of the new alternative) in the HSR $(15 \%, 20 \%$ and $30 \%$ ), Table 11 shows the demand forecast for the new HSR in the first year of operation. Even in the most favorable hypothesis of $30 \%$ of generated traffic, the demand for the new HSR would not exceed 3.2 million passengers per year. This figure does not cope with the high expectations of RENFE (the company that operates railways in Spain) that predicted an entrance share for the HSR of $60 \%$. Figure 2 compares predictions of the model with real volumes of traffic in the first year of operation of the HSR (2008). Although it is difficult to know how many new trips are going to be generated as a consequence of the introduction of the new rail alternative, the hypothesis that better fits the real data for the year 2008 is $10 \%$, which represents about 0.25 million new passengers per year.

Table 10: Predicted market shares.

\begin{tabular}{lccc}
\hline & \multicolumn{3}{c}{ Predicted market share } \\
\cline { 2 - 4 } Mode & Actual (without HSR) (\%) & Future (with HSR) (\%) & $\%$ \\
\hline Car driver & 6 & 4 & $-30 \%$ \\
Car passenger & 4 & 3 & $-29 \%$ \\
Bus & 8 & 6 & $-32 \%$ \\
Train/HSR & 12 & 36 & $190 \%$ \\
Plane & 69 & 51 & $-26 \%$ \\
\hline
\end{tabular}




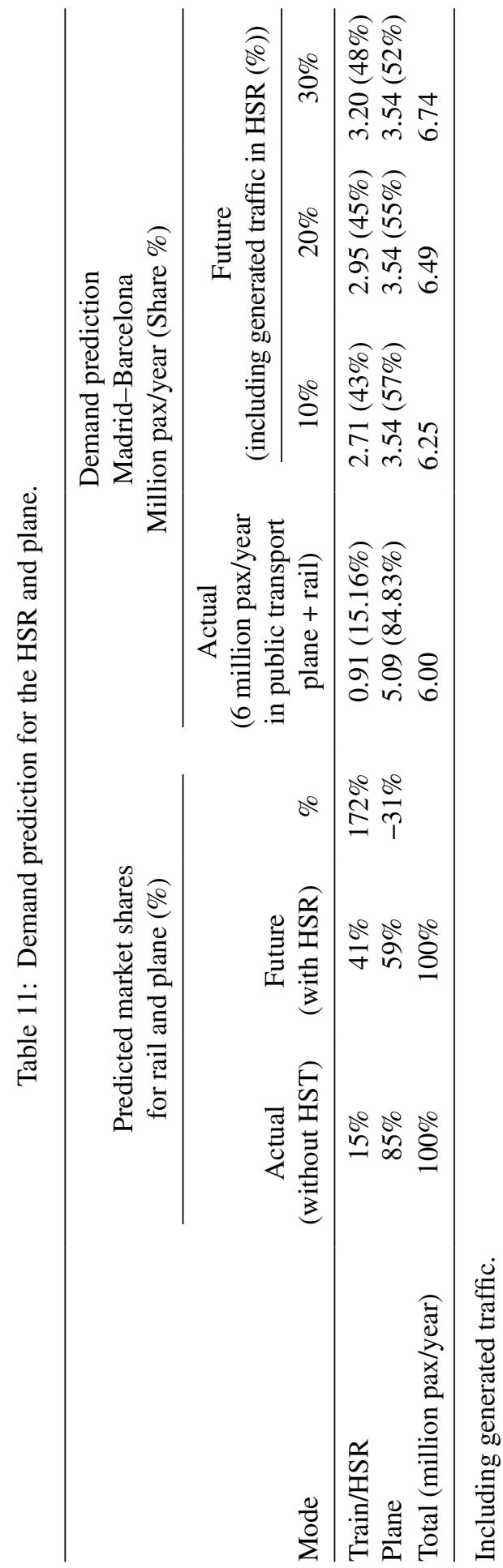




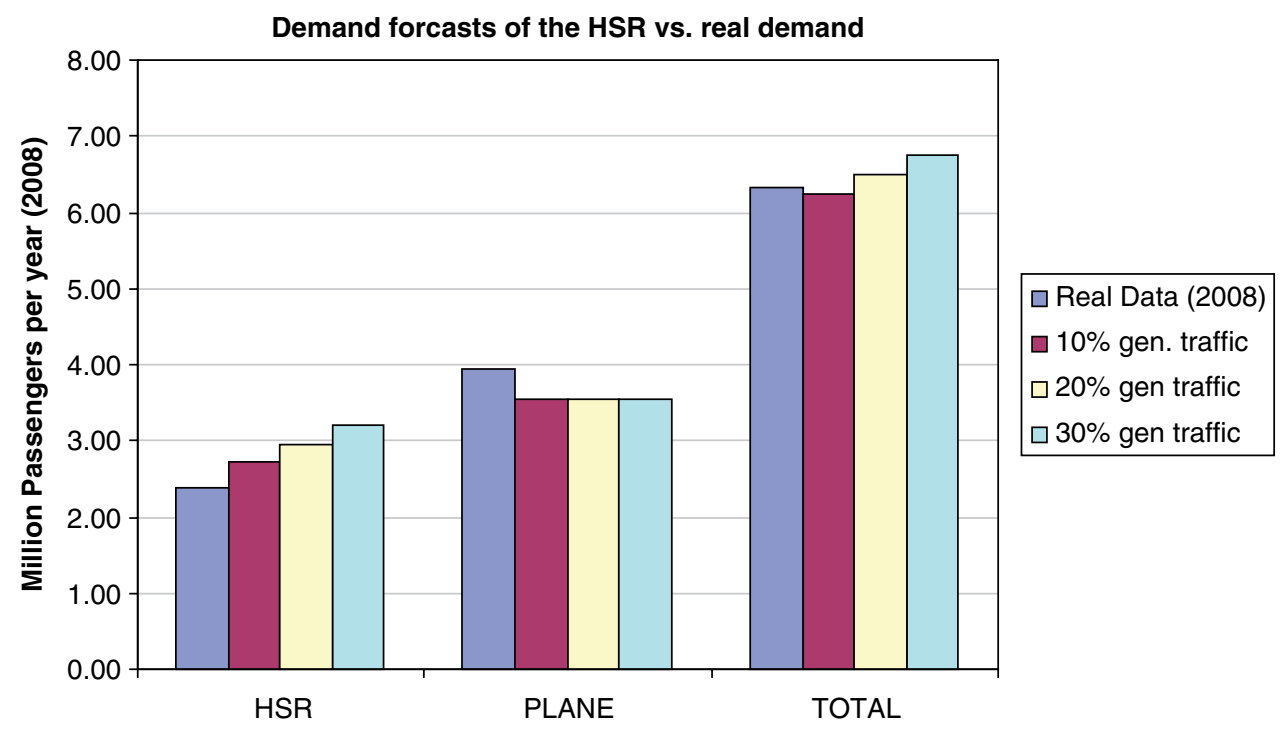

Figure 2: Demand predictions vs. actual volume of traffic. Year 2008.

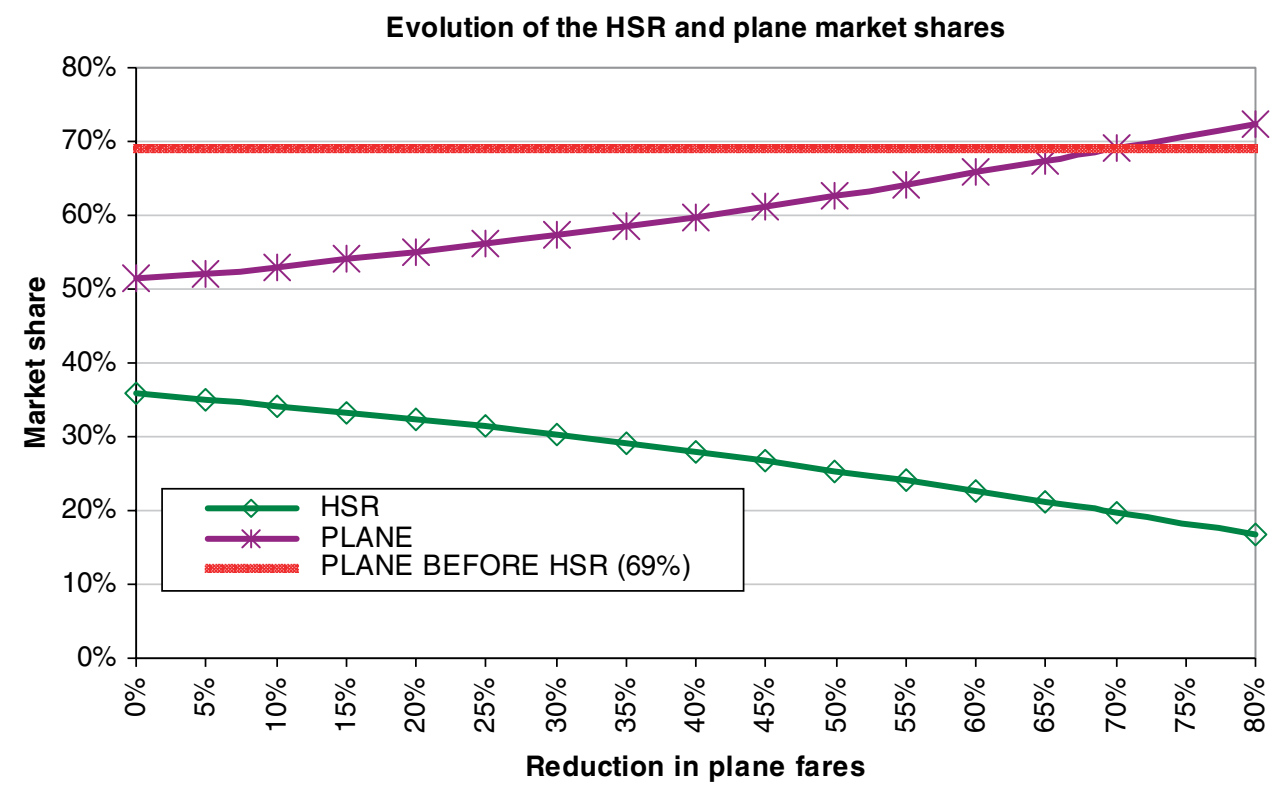

Figure 3: Reaction of plane to HSR entrance.

\subsection{Potential competition}

In this section we analyze how competition is going to be held in this market according to our model. Figure 3 shows the reaction of the plane, in terms of price competition, to the HSR entrance (the other modes (car and bus) which present a marginal share in this corridor are not shown in the 


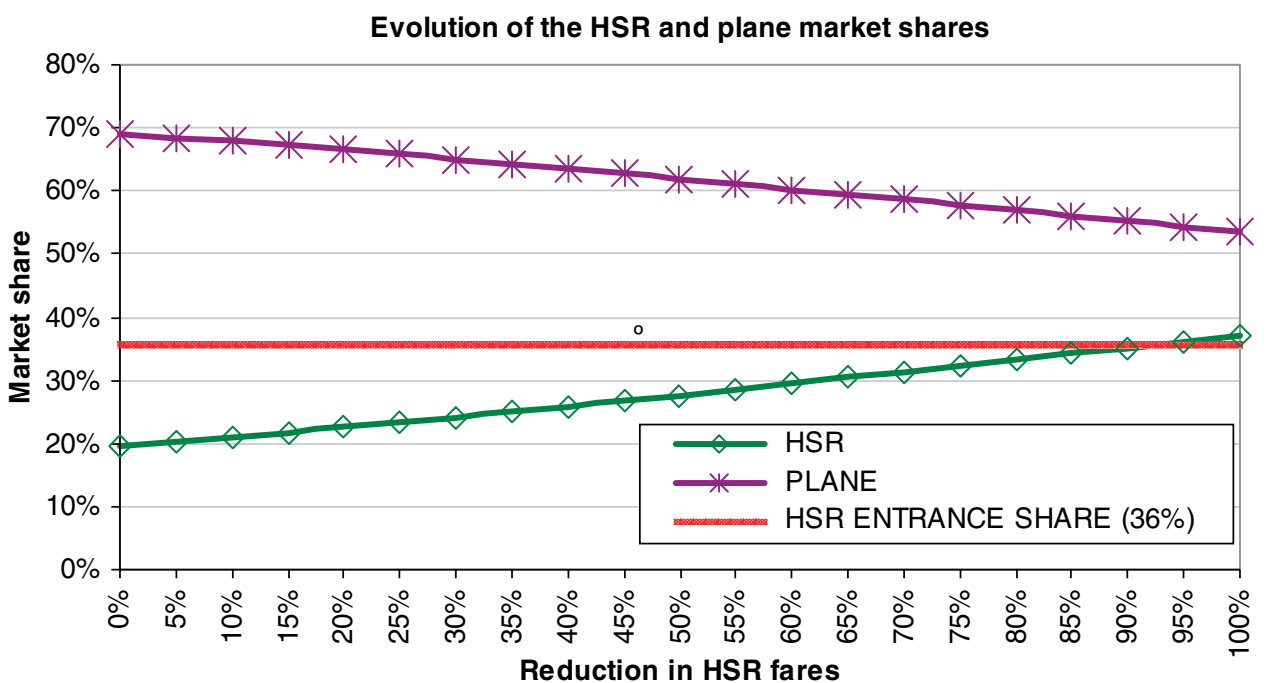

Figure 4: Reaction of the HSR to the reduction of plane fares.

figure). The model predicts an entrance market share for the HST of 36\% (Table 10). If the plane reacts to the HSR entrance, a reduction in fares of $70 \%$ would be needed in order to attain the previous market share before the HSR entrance (69\%), leaving for the HSR a $20 \%$ of the market. In after the plane strategy, the HSR reacts lowering its own fares, a reduction of $95 \%$ would be required in order to obtain the HSR entrance share of $36 \%$ (Fig. 4).

Whether these pricing policies could be exerted by airlines and RENFE is out of the scope of the present paper. However, airlines and bus companies are accusing RENFE, a public firm, of anti-competitive behavior because prices are based on political decisions that do not reflect the infrastructure costs.

\section{CONCLUSIONS}

Most infrastructure projects, such as the HSR between Madrid and Barcelona, require an ex ante evaluation before compromising public funds. However, in practice, it is common to observe that these analyses are biased and tend to exaggerate the competitive advantages of the HSR. The special attention paid within the European transport policy to the rail sector, has created an important debate among economists about the social profitability of the HSR projects, which depend to a high extent on the volume of traffic as well as the travelers willingness to pay for improvements in the quality of the service. (All the willingness to pay measures corresponding to this corridor are presented in Ref. [44].) In fact, the value of the different components of the travel time in this corridor represents substantial figures: $10.17 € / \mathrm{h}$ for the waiting time, $22.41 € / \mathrm{h}$ for in-vehicle travel time for business trips and $46.45 € / \mathrm{h}$ for the access and egress time [44].

In this paper we have analyzed the potential demand for new HSR services in high dense air transport corridors like the route linking Madrid and Barcelona. The analysis is based on the estimation of a discrete choice model using a mixed RP/SP dataset. RP data provide information about individuals' preferences in a real market; while SP data provide travelers' stated behavior in the presence of new alternatives. The utility function for the different RP alternatives is defined in terms of the main level-of-service attributes: travel costs, the different components of total travel time and service 
frequency. For the SP alternatives (plane and HSR), we also include the latent variables reliability and comfort. The model detects a source of correlation between the plane and conventional train. This correlation is expected to be higher after the entrance of the HSR as this mode is a closer substitute for the air transport.

The analysis carried out shows that the expected volume of demand for the HSR in the MadridBarcelona corridor (between 2.7 and 3.2 million passengers per year) is not enough to guarantee a positive social benefit of this project. De Rus and Román [11] point out that at least 17 million passengers would be needed to obtain a positive net present value in this corridor.

These results, jointly with the low rate of return of HSR projects, cast some doubts on the potential competition that HSRs can exert in markets that have been characterized in the past by a high frequency of air services. For this reason, policy makers should take into account that the amount of money dedicated to build very expensive infrastructures could have had alternative uses that might be more efficient.

\section{REFERENCES}

[1] Laird, J.J., Nellthorp, J. \& Mackie, P.J., Network effects and total economic impact in transport appraisal. Transport Policy, 12, pp. 537-544, 2005. doi:10.1016/j.tranpol.2005.07.003

[2] Martin, F., Justifying a high-speed rail project: social value vs. regional growth. The Annals of Regional Science, 31, pp. 155-174, 1997. doi:10.1007/s001680050043

[3] Nash, C.A., The case for high speed rail, Institute for Transport Studies, The University of Leeds Working Paper 323, Leeds, 1991.

[4] Sichelschmidt, H., The EU programme "trans-European networks" - critical assessment. Transport Policy, 6, pp. 169-181, 1999. doi:10.1016/S0967-070X(99)00018-9

[5] Short, J. \& Kopp, A., Transport infrastructure: investment and planning. Policy and research aspects. Transport Policy, 12, pp. 360-367, 2005. doi:10.1016/j.tranpol.2005.04.003

[6] Van Exel, J., Rienstra, S., Gommers, M., Pearman, A. \& Tsamboulas, D., EU involvement in TEN development: network effects and European value added. Transport Policy, 9, pp. 299-311, 2002. doi:10.1016/S0967-070X(02)00016-1

[7] Vickerman, R.W., High-speed rail in Europe: experience and issues for future development. The Annals of Regional Science, 31, pp. 21-38, 1997. doi:10.1007/s001680050037

[8] de Rus, G. \& Inglada, V., Análisis coste-beneficio del tren de alta velocidad en España. Revista de Economía Aplicada, 3, pp. 27-48, 1993.

[9] de Rus, G. \& Inglada, V., Cost-benefit analysis of the high-speed train in Spain. The Annals of Regional Science, 31, pp. 175-188, 1997. doi:10.1007/s001680050044

[10] Levinson, D., Mathieu, J.M., Gillen, D. \& Kanafani, A., The full cost of high speed rail: an engineering approach. The Annals of Regional Science, 31, pp. 189-215, 1997. doi:10.1007/ s001680050045

[11] de Rus, G. \& Román, C., Análisis económico de la línea de alta velocidad Madrid-Barcelona. Revista de Economía Aplicada, 42, pp. 35-80, 2006.

[12] Steer Davies Gleave. High Speed Rail: International Comparisons, Commission for Integrated Transport: London, 2004.

[13] Atkins, High-speed Line Study, Department of Environment, Transport and the Regions: London, 2004.

[14] de Rus, G. \& Nombela, G., Is the investment in high speed rail socially profitable? Documento de trabajo EIT, Universidad de Las Palmas, 2004.

[15] Martín, J.C. \& Nombela, G., Microeconomic impacts of investments in high speed trains in Spain. The Annals of Regional Science, 41, pp. 715-733, 2007. doi:10.1007/s00168-007-0116-8 
[16] Blum, U., Haynes, K.E. \& Karlsson, C., Introduction to the special issue: the regional and urban effects of high-speed trains. The Annals of Regional Science, 31, pp. 1-20, 1997. doi: $10.1007 / \mathrm{s} 001680050036$

[17] Haynes, K.E., Labor markets and regional transportation improvements: the case of highspeed trains: an introduction and review. The Annals of Regional Science, 31, pp. 57-76, 1997. doi: $10.1007 / \mathrm{s} 001680050039$

[18] Plassard, F., High speed transport and regional development. European Conference of Ministers of Transport (eds) Regional Policy Transport Network. OECD, Paris, 1994.

[19] Vickerman, R.W., The regional impacts of Trans-European networks. The Annals of Regional Science, 29, pp. 237-254, 1995. doi:10.1007/BF01581809

[20] Fröidh, O., Market effects of regional high-speed trains on the Svealand line. Journal of Transport Geography, 13(4), pp. 352-361, 2005.

[21] Gutiérrez, J., González, R. \& Gómez, G., The European high-speed train network: predicted effects on accessibility patterns. Journal of Transport Geography, 4(4), pp. 227-238, 1996. doi:10.1016/S0966-6923(96)00033-6

[22] Gutiérrez, J., Location, economic potential and daily accessibility: an analysis of the accessibility impact of the high-speed line. Journal of Transport Geography, 9, pp. 229-242, 2001. doi:10.1016/S0966-6923(01)00017-5

[23] Martín, J.C., Gutiérrez, J. \& Román, C., Data Envelopment Analysis (DEA) index to measure the accessibility impacts of new infrastructure investments: the case of the high-speed train corridor Madrid-Barcelona-French border. Regional Studies, 38(6), pp. 697-712, 2004. doi:10.1080/003434042000240987

[24] Vickerman, R.W., Spiekermann, K. \& Wegener, M., Accessibility and economic development in Europe, Regional Studies, 33(1), pp. 1-15, 1999. doi:10.1080/00343409950118878

[25] Combes, P.P \& Linnemer, L., Intermodal competition and regional inequalities. Regional Science and Urban Economics, 30, pp. 131-184, 2000.

[26] Koppelman, F.S. \& Wen, C.H., Nested logit models: which are you using? Transportation Research Record, 1645, pp. 1-7, 1998. doi:10.3141/1645-01

[27] Bhat, C.R., Accommodating variations in responsiveness to level-of-service measures in travel mode choice modelling. Transportation Research Part A, 32(7), pp. 495-507, 1998. doi:10.1016/S0965-8564(98)00011-1

[28] KPMG Peat Marwick in association with ICF Kaiser Engineers, Inc., Midwest System Sciences, Resource Systems Group, Comsis Corporation and Transportation Consulting Group. Florida High Speed and Intercity Rail Market and Ridership Study: Final Report, Submitted to Florida Department of Transportation, 1993.

[29] Hensher, D.A., A practical approach to identifying the market potential for high speed rail: a case study in the Sydney-Canberra corridor. Transportation Research Part A, 31(6), pp. 431-446, 1997. doi:10.1016/S0965-8564(97)00001-3

[30] González-Savignat, M., Competition in air transport. The case of the high speed train. Journal of Transport Economics and Policy, 38(1), pp. 77-108, 2004.

[31] Park, Y. \& Ha, H.-K., Analysis of the impact of high-speed railroad service on air transport demand. Transportation Research Part E, 42, pp. 95-104, 2006. doi:10.1016/j.tre.2005.09.003

[32] Ahern, A.A. \& Tapley, N., The use of stated preference techniques to model modal choices on interurban trips in Ireland. Transportation Research Part A: Policy and Practice, 42(1), pp. 15-27, 2008. doi:10.1016/j.tra.2007.06.005

[33] Rigas, K., Boat or airplane? Passengers' perceptions of transport services to islands. The example of the Greek domestic leisure market. Journal of Transport Geography, 17(5), pp. 396-401, 2009. doi:10.1016/j.jtrangeo.2008.07.005 
[34] Ortúzar, J. de D. \& Simonetti, C., Modelling the demand for medium distance air travel with the mixed data estimation method. Journal of Air Transport Management, 14, pp. 297-303, 2008.

[35] Ortúzar, J. de D. \& Willumsen, L.G., Modelling Transport, 3rd edn. John Wiley \& Sons: Chichester, 2001. doi:10.1016/j.jairtraman.2008.08.002

[36] Koppelman, F.S. \& Bhat, C., A self instructing course in mode choice modeling: multinomial and nested logit models. U.S. Department of Transportation, Federal Transit Administration, 2006.

[37] Train, K., Discrete Choice Methods with Simulation, Cambridge University Press: Cambridge, 2003.

[38] Ben-Akiva, M.E. \& Morikawa, T., Estimation of travel demand models from multiple data sources. Proceedings 11th International Symposium on Transportation and Traffic Theory, Yokohama, 1990.

[39] Bradley, M.A. \& Daly, A.J., Estimation of logit choice models using mixed stated preference and revealed preference information. Understanding Travel Behavior in an Era of Change, ed. P.R. Stopher \& M. Lee-Gosselin, Pergamon: Oxford, pp. 209-32, 1997.

[40] Jara-Díaz, S.R. \& Farah, M., Transport demand and users' benefits with fixed income: the goods/leisure trade-off revisited. Transportation Research, 21B, pp. 165-170, 1987. doi:10.1016/0191-2615(87)90014-2

[41] Jara-Díaz, S.R., Time and income in travel choice: towards a microeconomic activity-based theoretical framework. Theoretical Foundations of Travel Choice Modeling, ed. T. Garling, T. Laitila \& K. Westin, Elsevier Science: Nueva York, pp. 51-74, 1998.

[42] Louviere, J.J., Hensher, D.A. \& Swait, J.D., Stated Choice Methods: Analysis and Application, Cambridge University Press: Cambridge, 2000.

[43] Cherchi, E. \& Ortúzar, J. de D., On fitting mode-specific constants in the presence of new options in RP/SP models. Transportation Research, 40A, pp. 1-18, 2004.

[44] Román, C., Espino, R. \& Martín, J.C., Analyzing competition between the high speed train and alternative modes. The case of the Madrid-Zaragoza-Barcelona Corridor. Journal of Choice Modelling, 3(1), pp. 84-108 2010. 